\title{
Augmentation of situational awareness by fault passage indicators in distribution network incorporating network reconfiguration
}

\author{
Tanmay Jain*, Debomita Ghosh and Dusmanta Kumar Mohanta
}

\begin{abstract}
Power distribution systems are profoundly inclined to disturbances like untimely switching of breakers \& relays, sympathetic tripping, and uncertainties regarding fault location. Thus, system stability and reliability are greatly affected. In this way, situational awareness and system integrity are the crucial factors in developing power system security, as it empowers successful decision making \& timely reaction by the operators to any disturbance and also maintaining continuity of power supply. This paper focuses on the enhancement of situational awareness by fault location through fault passage indicators (FPI) to improve nominal impedance-based methods in distribution networks. Also, the proposed method is validated by comparing it with Intelligent Electronic Device (IED) based fault location method. Further, simultaneous reconfiguration of the system is incorporated to maintain the continuity of supply. The analysis has been tested on IEEE 33 bus distribution system.
\end{abstract}

Keywords: Situational awareness, Fault passage Indicator, Tie switching, Reconfiguration

\section{Introduction}

Nowadays blackouts in power systems is a major concern for utilities, especially in distribution systems. As the complexity in present networks is increasing, an abnormality at any side may result in cascading outages [1]. Due to this, the concept of situational awareness came into the picture. Situational Awareness (SA) is defined as "the view of the components in a situation inside a volume of existence, the cognizance of their significance, and the projection of their status sooner rather than later". The sufficient information required for SA is divided into three levels i.e., perception, comprehension, and projection [2].

Quite a few researches have been carried out on situational awareness and system integrity in power systems. In [3], panteli \& kirschen discussed major challenges in implementing SA in power systems which further comprises its applications in the power industry. Mohagheghi in [4], explained about SA in automated systems by

\footnotetext{
* Correspondence: tanmayjain.1994@gmail.com

Department of Electrical and Electronics Engineering, Birla Institute of Technology, Mesra, Ranchi, India
}

taking an intelligent scheme based on graph-theoretic fuzzy cognitive maps (FCM) i.e., external or internal failures and degradation of an event has been proposed by heuristic rules and unsupervised learning methods. Kundu and Pradhan in [5], presented that uncertainties like faults, loss of load or generator outage leading to unwanted relay operations and makes system unhealthy and can be prevented by system integrated protection scheme (SIPS) by locating fault locations, and other disturbance points in the system. Fault location in power systems, especially in the distribution network, is essential as most of the disturbances occur at the load side.

Many approaches have been carried out considering impedance-based fault location methods in distribution networks. In [6], Gong \& Guzman proposed fault location technique that uses current and voltage measurements obtained from digital relays during fault conditions and adjusts the nonhomogeneous characteristics of the distribution. The model proposed consist of relay, recloser and FCIs. In [7], Abo-shady et.al proposed an analytical approach for determining the fault location in distribution networks in presence of distributed 
generation (DG). The proposed technique presented a method to overcome the error caused due to distribution of load along the feeder, non-homogenous sections, high DG penetration level, and different fault resistance values. Salim et al. in [8], presented improvements related to the capacitive effect consideration on impedance-based fault location techniques, by considering an exact line segment model for the distribution line and also new algorithm is developed which considers line shunt admittance matrix. Mora-Florez et al. in [9], proposed a comparative analysis of the performance of 10 impedance-based fault location methods for power distribution networks. The limitation of the above techniques is that in most cases unique identification of location of the fault is not obtained. This brings the concept of fault locators or indicators (FL) in distribution network.

FLs or FIs are located in a substation of the distribution network, are used to find the location of fault. FLs calculate the distance to the fault by calculating faulty line impedance. In [10], Ho, Lee \& Lin proposed the allocation of fault indicators (FI) by an immune algorithm in order to minimize the total cost of customer service outage and investment cost of fault indicators. Farajollahi, Firuzabad and Safdarian in [11, 12] proposed mixed-integer programming (MIP) approach for allocation of fault indicators and also worked on simultaneous placement of FI and sectionalizing switches in distribution network by considering reliability perspective. In [13] Shahsavari, Mazhari, Fereidunian \& Lesani considered a multi-objective formulation approach by modified particle swarm optimization (MPSO) for the placement of FI in distribution system. Usida, Coury, Flauzino and da Silva in [14] proposed an evolutionary computation approach for solving the problem of placement of FI's in distribution networks. The drawback of FLs is that faulty line impedance depends on four parameters i.e., distance to fault (line length), fault type (fault impedance), crosssection of the lines and the number of branches from the substation bus. To overcome this drawback, fault passage indicators (FPIs) are installed in the network. FPIs determine the location of the fault by detecting the passage of fault current through the lateral coming from bus on which they are located. By placing the FPIs at suitable locations in a distribution network, the fault location time increases, which is in between the last indicator that detected fault current and the next indicator that did not indicate.

The most common makers of FPIs in distribution systems are Siemens (SICAM FPI), Schneider Electric (Flair 21D) [15, 16], etc.

Features of FPI:

1. Simple \& economical for fast fault location in modern distribution networks.
2. Reliable detection and reporting of ground \& phase faults in radial and open-ring networks.

3. They do not require auxiliary voltage i.e., they are self-sustaining because of the presence of lithium battery.

4. Noise immune plastic fiber-optic connections between sensors \& FPI.

Locating the exact fault location in a distribution system which ultimately sends a signal to relay to operate is one of the key steps in promoting SA. For this the fault passage indicator (FPI) is used which is defined as "the devices that give the signal regarding the exact location of fault i.e., the passage of fault current in the system to the crew or operator which ultimately helps in sending the signal to the protection system". A few researches on FPIs have been carried out. In [17], Almeida et al. proposed the algorithm for the optimal placement of FPI in the distribution system by binary approach and optimization through Chu-Beasley genetic algorithm (CBGA) which ultimately improves impedance-based approach. In [18], Chollet et al., proposed an overview of comparison between FPIs and protection relay over phase and earth fault detection and developed an algorithm for the earth fault detection in MV networks. In [19], Altonen et al., proposed a novel approach of FPI indication by using multi-frequency neutral admittance measurement together with a cumulative phasor summing technique in MV networks. In [20], Mršić et al., outlined the importance of FLs with FPIs and developed an algorithm for determining the location of FPIs in distribution network with installed FLs. Zeljković et al., in [21], assessed the performance of FLs and FPIs separately and by combining them together in distribution networks using non-sequential Monte-Carlo simulation and further highlighted the advantages of FPIs over FLs.

From the above literature survey, it can be concluded that many researches are done towards fault identification and optimal placement of FPI in different power system networks but in most cases it does not outlines the unique identification of the fault and operator's decision making \& action plan (comprehension) and future state of the system (projection). This paper focuses on the enhancement of SA by perceiving data of the fault and determining its exact (unique) or suspected locations by FPI placement using binary approach so to improve the impedance-based approach. Also, the proposed method is compared with impedance-based fault location method using IEDs \& FCI (FPI). Further, on the basis of FPI placed, faults are created at different locations and then simultaneously tie switching or reconfiguration is incorporated in order to maintain continuity of supply at all buses which accounts on the timely and corrective action plan in regard to the perceived data 
i.e., comprehension. This tie switching or reconfiguration is carried out on the basis of power loss minimization by backward forward sweep load flow technique. The efficacy of this analysis is tested on IEEE 33 bus distribution system.

The paper has been categorized as follows. Section 2 illustrates a brief review of SA in the distribution network. Section 3 outlines fault susceptibility by FPI placement using binary approach. Further, in Sect. 4, tie switching incorporation is outlined on the basis of power loss minimization by backward forward sweep load flow method. In Sect. 5 the experimental results of IEEE 33 bus distribution network are discussed. The conclusion of the paper is comprised in Sect. 6.

\section{Brief review of situational awareness in distribution network}

SA in distribution networks is very important as most of the disturbances occur at the customer side. Deployment of FPIs in distribution networks enhances SA as retrieval of information from FPIs (perception) makes the operator in control room aware regarding the fault and enhances his decision making by analyzing it \& plan the necessary actions (comprehension) and which further decreases restoration time \& cascading outages can be prevented (projection). The three levels of SA in power systems is depicted in Fig. 1.

SA is divided into three levels:

1. Perception - In this level, to carry out SA in power system data or information is retrieved by real-time measurements, electronic displays, etc. Along with this communication between crew to share the information is equally important. For ex, if any fault occurs in a system, subsequent devices and its displays give the information to the crew in the control room.

2. Comprehension - After the first level, the perceived information is analyzed and according to crew objectives its action plan is decided.
3. Projection - In this level, future system state and time for actions implementation contributes towards developing strategies to avoid undesirable events.

\section{Fault susceptibility by FPI placement}

As it is explained already, the first level of SA i.e., perception which deals with the retrieval of information using real-time measurements, electronic displays, indicators, etc. Here triggering of FPI in distribution network indicates the occurrence of fault in the network and this information is sent to the operator. Suppose the network detects the fault without installation of FPI, the faulty points which will be obtained will create uncertainty regarding the exact location of fault (shown in Table 1). This wrong information percepted by the operator will result in an increase in the fault location time and ultimately hamper the power supply to the affected areas for a longer time. So, by installing FPIs in the network, the appropriate information will be percepted to the operator personnel, as only the concerned FPI(s) will trigger and the suspected location of fault will be obtained. Hence, the appropriate information regarding any abnormal event (fault) results in enhancement of SA.

Distribution systems are vulnerable to faults by different sources, for example, extreme climatic conditions and equipment failure. So as to improve the reliability of the system and keep away penalties, it is alluring for utilities to rapidly discover faulted areas and therefore diminish restoration time to enhance SA.

The utilization of FPIs to improve impedance-based approach is an intriguing methodology for electric utilities. It can accelerate the restoration time, staying away from penalties and enhancing quality indices. At the point when a fault happens downstream of the indicator, it naturally sends a signal to the supervisory control crew. Appropriately apportioning a specific number of

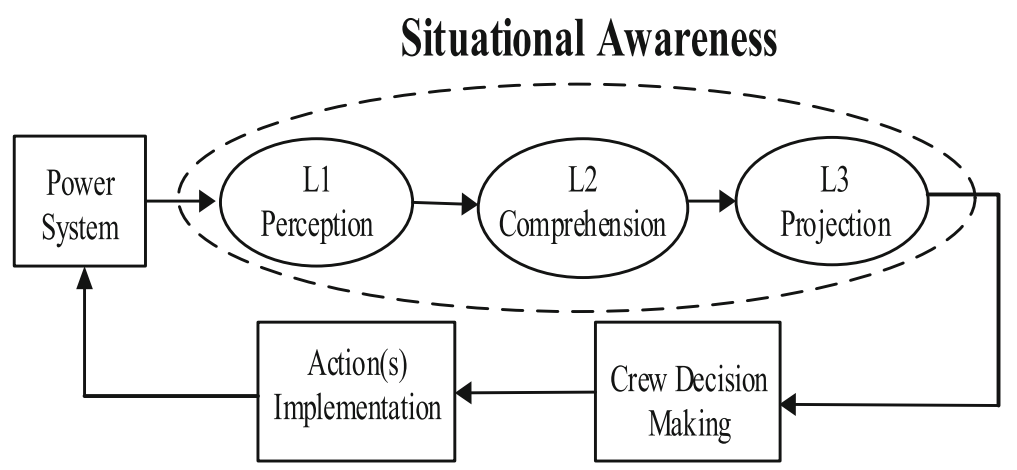

Fig. 1 Schematic model of SA in the power system 
Table 1 Comparison of discrete impedance points of fault in the network (Case 1) without \& with FPIs

\begin{tabular}{|c|c|c|}
\hline $\begin{array}{l}\text { Actual fault } \\
\text { impedance } \\
(\Omega)\end{array}$ & $\begin{array}{l}\text { Discrete impedance point of } \\
\text { fault detected by the system } \\
\text { without FPI }\end{array}$ & $\begin{array}{l}\text { Discrete impedance point } \\
\text { of fault detected by the } \\
\text { system with FPI }\end{array}$ \\
\hline 10 & 1 & 1 \\
\hline 20 & 2 & 2 \\
\hline 30 & 3,5 & $\begin{array}{l}5 \text { (if sensed by F1) } \\
3 \text { (if sensed by F2) }\end{array}$ \\
\hline 40 & $4,6,8,10$ & $\begin{array}{l}4 \text { (if sensed by F2) } \\
6,10 \text { (if sensed by F1) } \\
8 \text { (if sensed by F3) }\end{array}$ \\
\hline 50 & $7,9,11$ & $\begin{array}{l}\text { 7, } 11 \text { (if sensed by F1) } \\
9 \text { (if sensed by F3) }\end{array}$ \\
\hline 60 & 12 & 12 \\
\hline
\end{tabular}

FPIs may diminish or even wipe out the vulnerabilities related to the exact fault area. But, because of economic restrictions, it is difficult to locate FPIs at all the areas of the system to make it uncertainty free upon the happening of any fault $[17,18]$.

For determining the suspected locations of fault by FPI placement, two cases are possible in distribution networks i.e., when only one branch is coming out from substation bus and other is more than one is coming out from substation bus. Also, this approach is considered when only one fault has occurred in the network.

\subsection{Case 1: when only one branch from substation bus}

In a radial network, before placing FPIs the key step is to decide the impedance step size as it was done in nominal impedance-based methods [17].

Impedance step size is decided on the basis of Eq. (1) i.e.,

$$
0.1 \leq \Delta z \leq Z
$$

The impedance step size cannot be less than 0.1 because the results obtained by taking $\Delta z$ less than 0.1 is approximately similar to results obtained when $\Delta z=0.1$. By taking a smaller step size the computational time is increased means number of discrete impedance points are increased. Also, the upper limit of $\Delta z$ is the impedance of line between substation bus and adjacent bus because the placing of discrete impedance points starts from the substation bus. $\Delta z$ value is appropriate where at least one impedance point is placed in each line i.e., all the sections of the network are covered by the discrete impedance points. This concept has been explained in [17].

Consider Fig. 2a. which depicts a seven-bus radial feeder which contains seven buses and six branches. The values in braces are the branch numbers. The cumulative impedance is shown at every bus calculated from substation i.e., bus 1. For example, the impedance at bus $2(25 \Omega)$ is the sum of impedance at bus $1(0 \Omega)$ and branch $1(25 \Omega)$. Similarly, for bus 3 , the sum of impedance up to bus $2(25 \Omega)$ and branch $3(20 \Omega)$ and so on.

Here the impedance step size is $10 \Omega$ and $Z_{\circ}=25 \Omega$.

Now FPIs are placed in a radial network on any of the laterals whose source bus contains more than one lateral. Also, the fault location is determined through substation, so it is mandatory to place FPI at branch coming out from substation bus. Here in this network, 3 FPIs are placed at branch 1(F1), 3(F2) and 4(F3).

Suppose in Fig. 2a, the fault occurs at branch 1 at $10 \Omega$, so both nominal impedance-based technique and FPI placed at branch 1 will give one location of fault. But if the fault occurs at branch 2 at $30 \Omega$, the nominal impedance-based technique will give two suspected locations of fault i.e., at branch 2 and 3. In this fault case the FPI(s) will reduce or even eliminate this uncertainty by giving the exact location of fault i.e., at branch 2 . This comparison of fault locations in a network consisting of FPIs and without FPIs is depicted in Table 1.

From Table 1, it is concluded that by placing FPIs in the network the uncertainty regarding the fault is reduced or even eliminated which enhances SA considerably.

In accordance to FPIs placed, suspected locations for the fault can be drawn by binary approach. In this approach, the total number of combinations drawn for FPIs flagged status is given by Eq. (2)

$$
N=2^{m}
$$

Here, $m$ equal to 3 so, the number of combinations $N$ is equal to 8 . In accordance with it, following Table 2 using Eq. (3). is created showing the FPIs flag status and its corresponding discrete impedance points i.e., the suspected locations of fault in the network shown in Fig. 2b.

$$
K=[A \mid B]_{p \times q}
$$

Where,

$$
A \text { has order } R^{p \times\left(q-q^{\prime}\right)}
$$

$B$ has order $R^{p \times q}$

Unique location of the fault is governed by Eq. (4) for every combination of the FPI status.

$$
S_{j}=\left\{\begin{array}{c}
1 \text { Unique location of fault } \\
>1 \text { Multiple suspected locations }
\end{array}\right.
$$

It is important to note that when a fault occurs, all FPIs placed between substation \& fault location is flagged 1. 


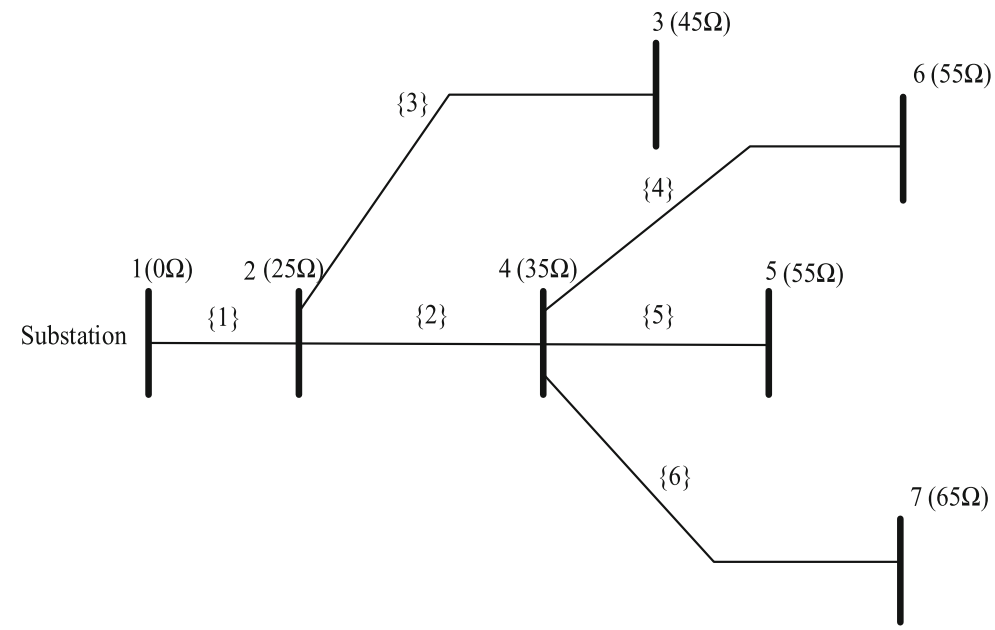

(a)

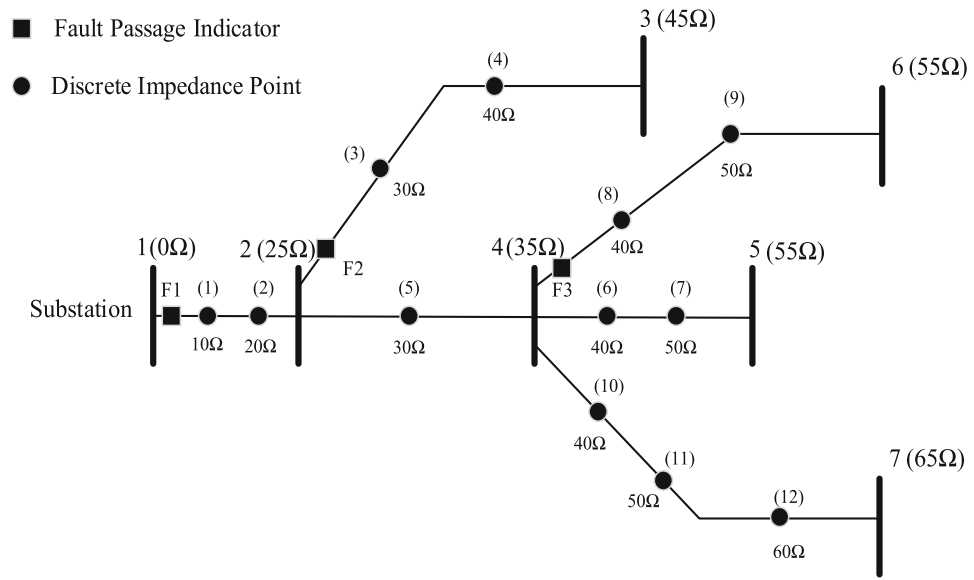

(b)

Fig. 2 a Seven bus radial feeder. b FPIs placed in seven bus feeder with an impedance step size of $10 \Omega$

Table 2 FPls flag status and corresponding discrete impedance points (suspected locations of fault) for Case 1

\begin{tabular}{|c|c|c|c|c|c|c|c|c|}
\hline \multicolumn{3}{|c|}{ FPIs status } & \multicolumn{6}{|c|}{ Discrete impedance points } \\
\hline F3 & $\mathrm{F} 2$ & F1 & $10 \Omega$ & $20 \Omega$ & $30 \Omega$ & $40 \Omega$ & $50 \Omega$ & $60 \Omega$ \\
\hline 0 & 0 & 0 & \multicolumn{6}{|c|}{ NO FAULT } \\
\hline 0 & 0 & 1 & $\begin{array}{l}1 \\
\text { (1) }\end{array}$ & $\begin{array}{l}1 \\
(2)\end{array}$ & $\begin{array}{l}1 \\
(5)\end{array}$ & $\begin{array}{l}2 \\
(6,10)\end{array}$ & $\begin{array}{l}2 \\
(7,11)\end{array}$ & $\begin{array}{l}1 \\
\text { (12) }\end{array}$ \\
\hline 0 & 1 & 0 & \multicolumn{6}{|c|}{ NO FAULT } \\
\hline 0 & 1 & 1 & 0 & 0 & $\begin{array}{l}1 \\
\text { (3) }\end{array}$ & $\begin{array}{l}1 \\
\text { (4) }\end{array}$ & 0 & 0 \\
\hline 1 & 0 & 0 & \multicolumn{6}{|c|}{ NO FAULT } \\
\hline 1 & 0 & 1 & 0 & 0 & 0 & $\begin{array}{l}1 \\
(8)\end{array}$ & $\begin{array}{l}1 \\
\text { (9) }\end{array}$ & 0 \\
\hline 1 & 1 & 0 & \multicolumn{6}{|c|}{ NO FAULT } \\
\hline 1 & 1 & 1 & 0 & 0 & $\begin{array}{l}1 \\
(3)\end{array}$ & $\begin{array}{l}2 \\
(4,8)\end{array}$ & $\begin{array}{l}1 \\
\text { (9) }\end{array}$ & 0 \\
\hline
\end{tabular}

It is important to note that when the impedance step size decreases the number of discrete impedance points increases. Also, from [17] it is proved that taking impedance step size less $0.1 \Omega$ will increase number of suspected locations and increases the computational time. So, the results obtained by taking step size less than or equal to $0.1 \Omega$ appeared to be same.

From Table 2 it is important to note that, when F1 is flagged zero regardless of flag status of F2 and F3, it will be a no-fault condition i.e., substation FPI flag status is vital in knowing that fault location in the network. Also, when F1 is flagged 1 and other FPIs are flagged 0 , then at $40 \Omega$ and $50 \Omega$ two suspected fault locations are seen at branch 5 and 6 , whereas, when FPI is not there in network the nominal impedance-based method will give four suspected locations of fault for $40 \Omega$. So, when FPIs are installed in a network the uncertainty regarding the fault location is reduced or even eliminated. Therefore, by placing FPIs, the fault identification time is reduced 
for the crew or operator as compared to nominal impedance techniques [17].

\subsection{Case 2: when multiple branches from substation bus} Now consider Fig. 3a which shows an eight bus feeder which has eight buses and seven branches. Here also impedance step size is $10 \Omega$. As discussed in case 1 , it is mandatory to place FPI(s) at the branches coming out from substation bus. So as seen in Fig. 3b, 4 FPIs are placed at branches 1(F1), 2(F2), 3(F3) and 7(F4).

In Fig. 3b, four FPIs are placed. Here the number of combinations of FPI flag status using Eq. (2) is equal to 16. Similarly, its FPIs flag status vs discrete impedance points table is created using Eq. (4).
Here no-fault condition will occur when both F1 and F2 will be flagged zero regardless of the status of F3 and F4.

\subsection{Case 3 (special case): when substation FPI has $80 \%$ reach}

Both above cases are designed when the substation bus FPI has $100 \%$ reach i.e., F1 will operate on $100 \%$ of the impedances present in its downstream i.e., $0 \Omega$ to $65 \Omega$.

So, if F1 is designed up to $80 \%$ of $65 \Omega$ i.e., $0 \Omega$ to $52 \Omega$ of the impedance present in its downstream then the FPIs location and suspected location of fault based on FPI flag status will be different from above cases.

In Fig. 2b, the number of FPI will increase when substation FPI has $80 \%$ reach i.e., instead of 3 FPIs, 5 FPIs

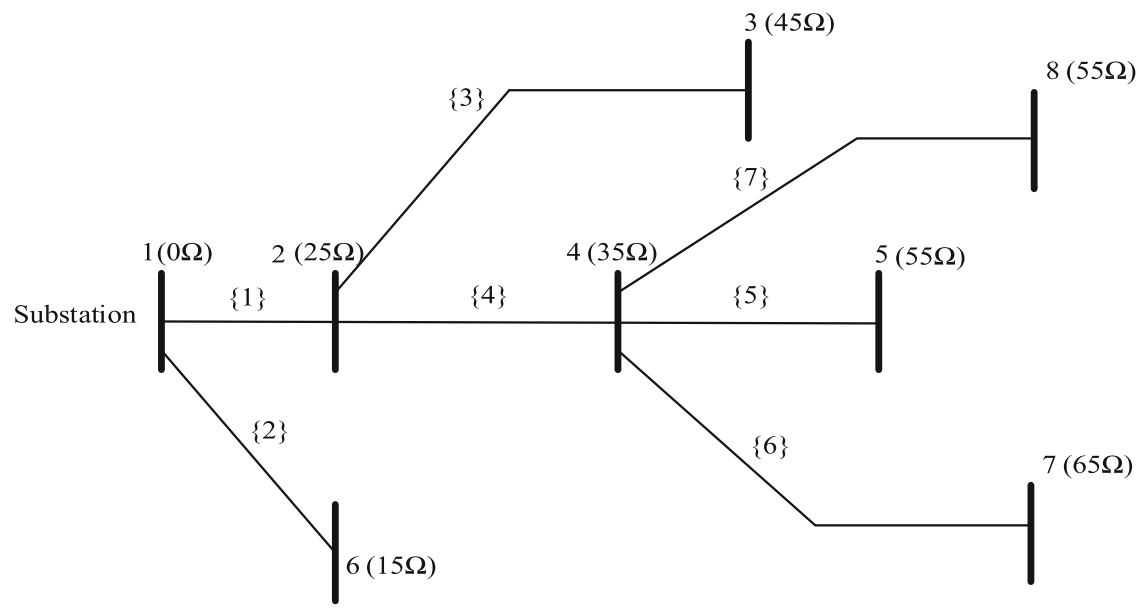

(a)

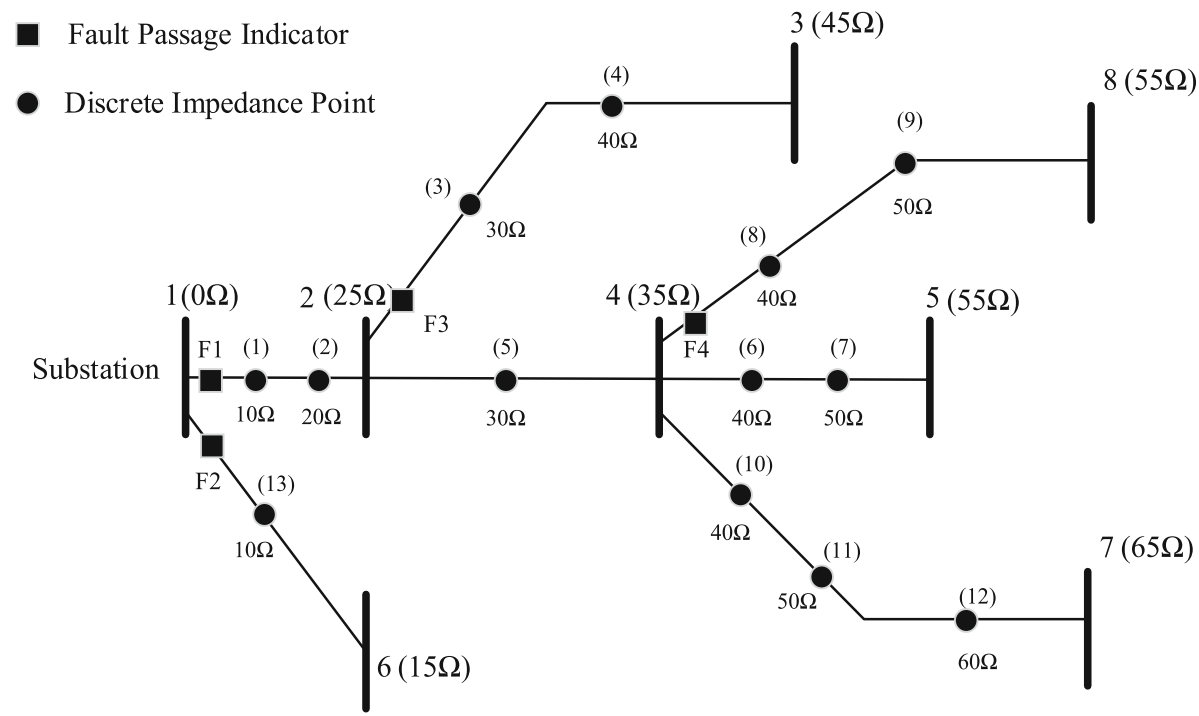

(b)

Fig. 3 a Eight bus radial feeder. b FPls placed in eight bus feeder with an impedance step size of $10 \Omega$ 
will be placed. The two more FPIs will be placed at $52 \Omega$ at branch 5(F4) and 6(F5) to uniquely locate faults after $52 \Omega$.

When substation FPI has $80 \%$ reach and other FPIs have not $100 \%$ reach, then the impedance step size of the network will change according to the impedance of the lines. In both cases, the number of FPIs will increase i.e., a new FPI will be placed where the reach of previous FPI in the lateral ends. For ex, in case 1 the reach of F2 is $80 \%$, so, it will cover up to $80 \%$ of $25-45 \Omega$ i.e., $41 \Omega$, hence a new FPI will be placed after $41 \Omega$ to cover rest of the section.

A generalized 4 bus radial feeder showing the FPIs and discrete impedance points are shown in Fig. 4. On the basis of network shown in Fig. 4, the flowchart for the FPI placement and identification of the suspected location of fault by binary approach is depicted in Fig. 5 to enhance perception of the network which is the first level of SA.

Time delay, false negatives, and false positives problem occur when FPI malfunctions i.e., either FPI fails to give the status when the fault has occurred or it triggers even if there is no fault. To deal with this condition when FPI malfunctions, the status of master FPI (substation FPI) and any voltage \& current magnitude measuring device like phasor measurement units (PMUs) will give the indication regarding the fault. The measuring device with master FPI in the network is just to reconfirm the detection of the fault if the adjoining FPI malfunctions i.e., they both operate parallel to each other.

- If there is no fault in the network and concerned FPI flagged 1 - In this case the status of master FPI will be flagged 0 which means there is no fault in the network.

- If there is fault in the network and concerned FPI flag status is 0 - In this case the status of master FPI will be flagged 1 and the PMU installed at the substation bus $\&$ at buses where more than one branches are coming out will let the crew know the distance to fault using Thevenin equivalent model by monitoring the voltage \& current magnitude.
- If both master and lateral FPI malfunctions (extreme case) - If both master and lateral FPI malfunctions, then the PMU data will give the information regarding the fault in the network.

Thus, in all the cases the determination of the exact fault location to take corrective measures i.e., perception in the power system network is enhanced ultimately enhancing the SA of the network.

Based on this binary approach, the analysis is tested on IEEE 33 bus distribution system which is discussed in Sect. 5 and further tie switching or reconfiguration is incorporated by backward forward load flow analysis to maintain continuity of supply which is the second stage of SA i.e., comprehension is explained in Sect. 4.

\section{Tie switching by backward forward load flow technique}

After retrieval of information regarding an event, the data related to it is analyzed and corrective \& timely actions are implemented. This is called the second level of SA i.e., comprehension. Here, when the perceived data of the fault is analyzed means by checking the FPI flag status the fault section is located (explained in Sect. 3), tie switching in the network is implemented means the tie associated with the faulty section is closed on the basis of minimum power loss to maintain the continuity of power supply. This timely implementation of necessary actions improves level 2 of SA (comprehension) and further enhances the SA.

The expansion in the power demand and high load density in the urban areas make the chore of distribution system complex. Because of low voltage level of distribution systems, active power losses are significantly more. To limit these losses, the status of normally closed sectionalizing switches and normally opened tie switches is modified by keeping up the radial topology of the system. This is called the reconfiguration of the system [22]. The merits of system reconfiguration are load balancing, minimizing power losses, improvement of voltage profile, enhancing power system security \& reliability and upgrade of power quality [23]. Many

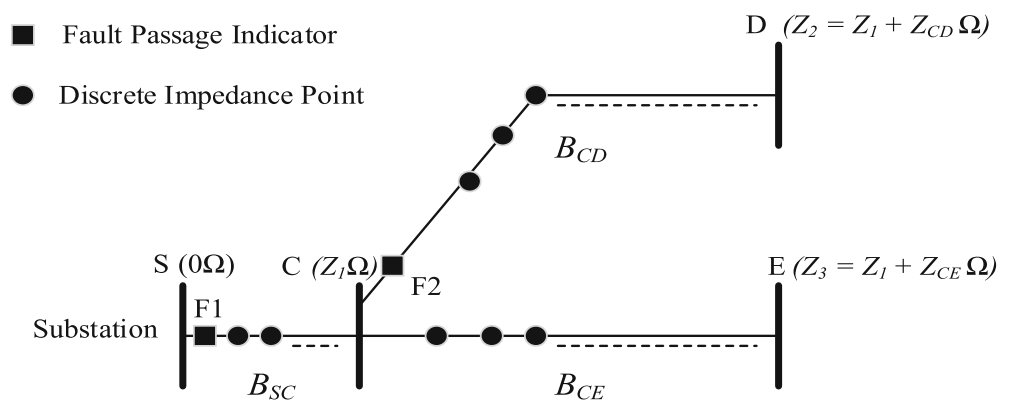

Fig. 4 Generalized 4 bus radial feeder 


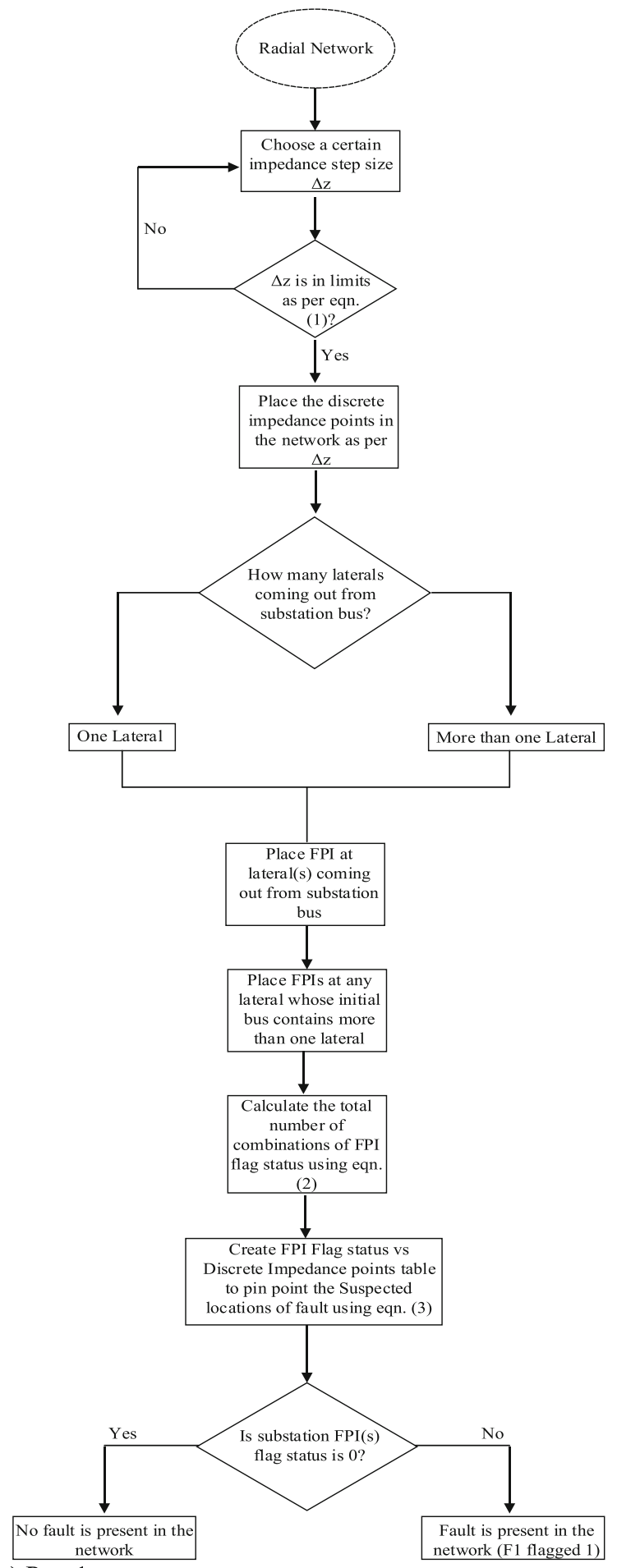

(a) Part 1

Fig. 5 Flow chart to enhance network perception

approaches have been proposed on network reconfiguration of distribution networks over the years. Baran and $\mathrm{Wu}$ in [24] highlighted the concept of distribution network reconfiguration by considering loss minimization and load balancing by branch exchange

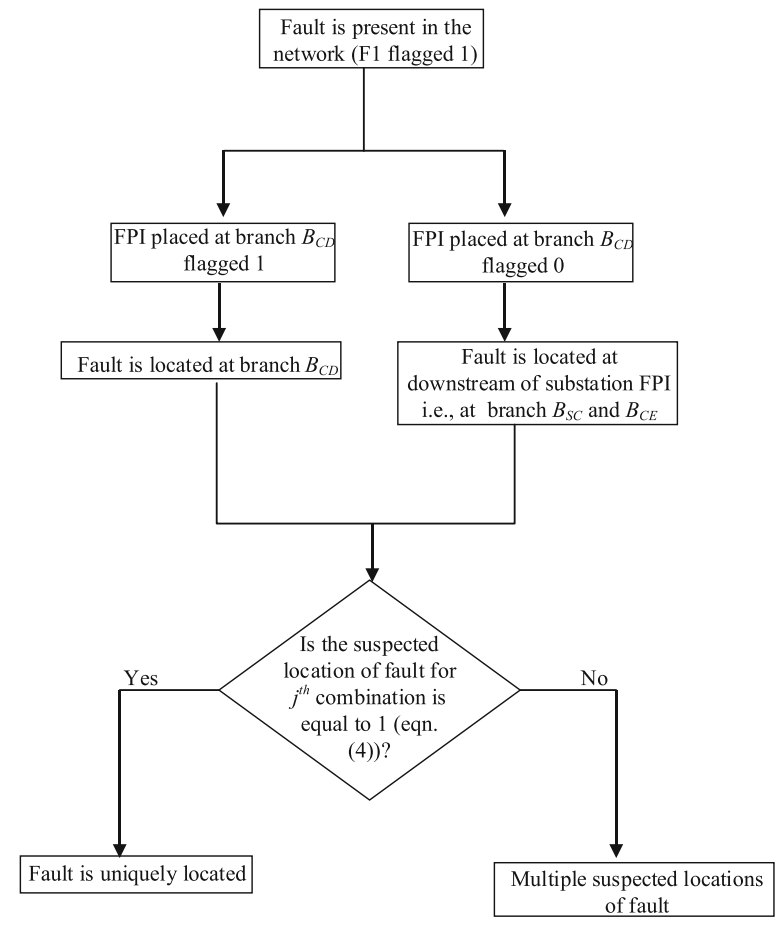

(b) Part 2 approach. In [23-27], reconfiguration of distribution networks is carried out by considering different objective functions and by using methods such as genetic algorithm (GA), fuzzy logic approach, particle swarm optimization (PSO), etc. 
The backward and forward load flow technique is utilized to comprehend the power flow examination of distribution networks with recursive equations. The backward and forward technique depends on the Kirchhoff's voltage and current law and in every emphasis, two calculation stages happen, the forward way and the backward way [28].

$$
\begin{aligned}
& S_{x}=P_{x}+j Q_{x} \\
& S_{x}=V_{x} I_{x}^{*}
\end{aligned}
$$

The apparent power at each bus in terms of active \& reactive power, voltage and current are given by Eqs. (5) and (6).

\subsection{Backward sweep}

The motive is to calculate current in each branch by considering the steady value of voltages found in the previous iteration while a voltage value is assumed initially for analysis. The backward way begins from the last node to the source node [29].

$$
\begin{aligned}
I_{x} & =\left(\frac{P_{x}+j Q_{x}}{V_{x}}\right)^{*} \\
I_{y} & =\left(\frac{P_{y}+j Q_{y}}{V_{y}}\right)^{*} \\
I_{x y} & =I_{y}+\sum_{r \in \alpha_{y}} I_{y r}
\end{aligned}
$$

For Fig. 6. the bus currents at each bus are calculated using Eqs. (7) and (8). The bus currents are summed up in backward path to give branch currents towards central bus which is at upstream by Eq. (9).

\subsection{Forward sweep}

This begins from the source node to the far end node means to compute the voltages at each bus while keeping the current acquired from previous iteration constant implying that the current acquired in the backward path will be constant amid the forward sweep. The determined voltages are compared with the predetermined

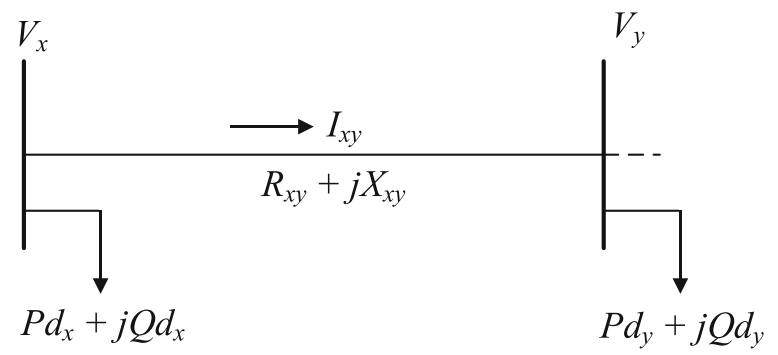

Fig. 6 Two Bus radial system voltage and if the error is inside tolerance limits, at that point the procedure is halted, also the line losses are figured out otherwise, the process is rehashed until criteria conditions are met $[29,30]$.

The bus voltages are calculated in the forward path from the upstream bus to the downstream bus. They are represented by branch currents and line parameters shown in Eq. (10).

$$
V_{y}=V_{x}-I_{x y}\left(R_{x y}+j X_{x y}\right)
$$

The active and reactive power losses are given by Eqs. (11) and (12).

$$
\begin{aligned}
& P_{L}=\sum I_{x y}^{2} \times R_{x y} \\
& Q_{L}=\sum I_{x y}^{2} \times X_{x y}
\end{aligned}
$$

The backward forward load flow algorithm is depicted from the flowchart in Fig. 7.

Tie switching or reconfiguration can be incorporated using backward forward sweep load flow technique. Whenever a fault occurs in a distribution network, loss of load takes place i.e., continuity of supply to the customers have been hampered. On this basis tie switching is carried out simultaneously i.e., normally opened tie switches are closed on the basis of minimum active power loss in order to feed the loads which are suffered by the faults.

The algorithm for tie switching on the basis of minimum active power loss by backward forward sweep load flow is as follows:

i. Run load flow when network is not subjected to any faults.

ii. Calculate the initial active power losses in a healthy condition.

iii. Now, if the fault occurs, identify the faulted line by FPI flag status.

iv. Correspondingly, check the impedance point of fault from FPI flag status vs discrete impedance points table.

v. Identify the possible associated ties for the faulted line by seeing the network topology.

vi. Close the associated ties one by one.

vii. Run load flow again on every tie closing and calculated the active power losses in each case using Eq. (11).

viii. From the data obtained of active power losses by running the load flow on every tie closing, choose the case where minimum power loss has occurred. 


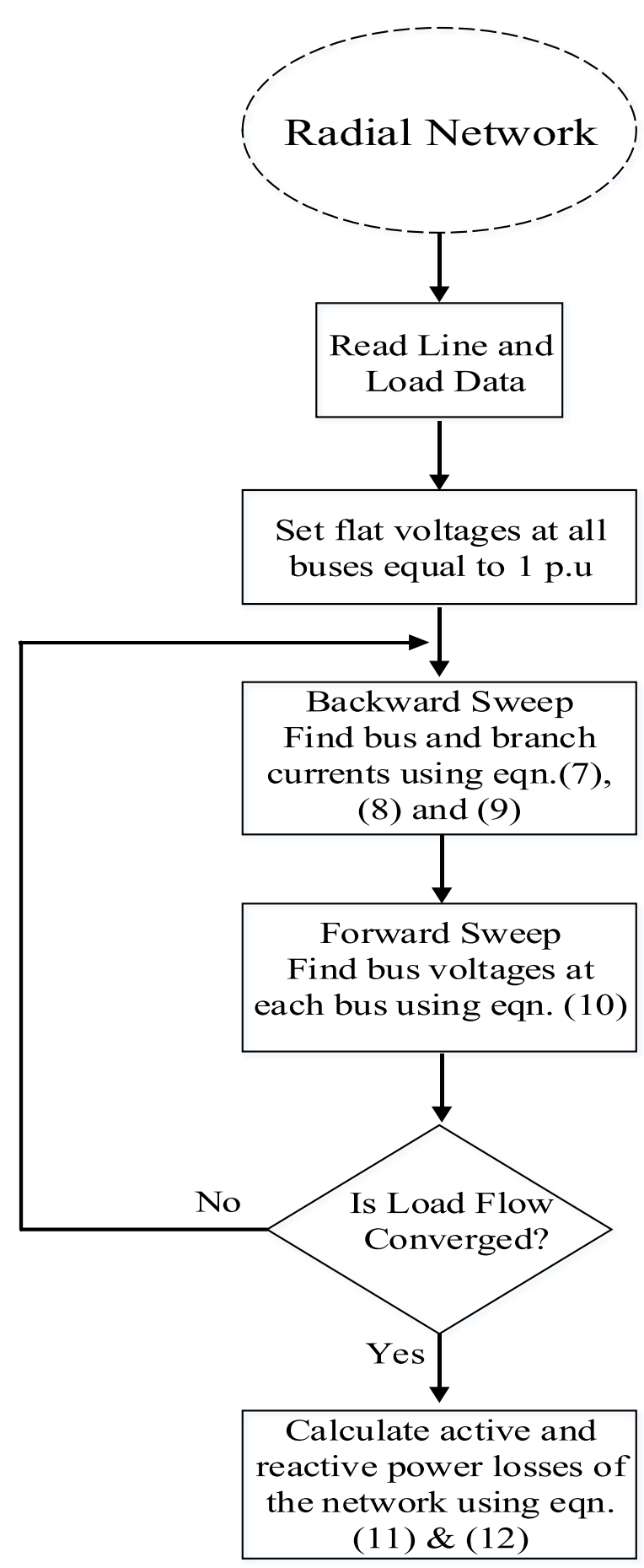

Fig. 7 Flow chart of Backward Forward Load Flow Technique

Finally, the level 3 of SA i.e., projection is implemented which accounts on the future behavior of the system in relation to perceived information Here, after timely action implementation, the future system state is analyzed and after the fault is cleared, the system is reverted back to its original state.

\section{Case study \& results}

\subsection{FPI placement and determination of suspected} locations

Single line diagram of IEEE 33 bus distribution network is represented in Fig. 8. The network consists of 37 branches and 33 buses which further includes (normally closed) 32 sectionalizing switches (normally closed) \& 5 tie switches (normally opened). The tie switches are $\mathrm{A}_{33}$, $\mathrm{A}_{34}, \mathrm{~A}_{35}, \mathrm{~A}_{36}, \mathrm{~A}_{37}$. The distribution system load is 3715 $\mathrm{kW} \& 2300 \mathrm{kVAr}$ and voltage is $12.6 \mathrm{kV}$. Branch 1 to 9 has the current capacity of 400A \& other lines (including tie lines) has 200A. The $V_{\min }$ and $V_{\max }$ are 0.95 p.u \& 1.05 p.u. $1000 \mathrm{~kW}$ DG sources are present on buses 6, 11 , and 29 taken from [31]. The impedance of each line is shown in Table 3.

As it can be seen from the network, line 3 to 5 , line 6 to 17 , line 22 to 24 , line 25 to 32 and line 18 to 31 are connected in series. Figure 9 depicts the equivalent network of IEEE 33 bus distribution system by combining the buses which are connected in series and also summing their impedances. Also, the placement of FPIs and the discrete impedance points in the equivalent network of IEEE 33 bus distribution network are shown in Fig. 9. As the FPIs are usually placed at the branches whose initial bus contains laterals. So according to it, four FPIs are placed at branch 1, 4, 5 and 7 on the equivalent network of IEEE 33 bus distribution system. Here $Z_{\text {。 }}=$ $0.1034 \Omega$ and impedance step size $\Delta z=0.1 \Omega$. Impedance step size should be in constraints using Eq. (1).

From Fig. 9, it has been observed that branch 1 has the FPI but its initial bus does not have any laterals. This is because if any fault happens in branch 1, then it cannot be uniquely located with the other FPIs placed on other branches. So, it is mandatory to place FPI at branch 1. Also, as branch 1 is connected to the substation, so, FPI placed at branch 1 plays a vital role in determining fault location in the network.

Using Eq. (2), the number of combinations of FPI status is equal to 16. Similar to the table created using Eq. (3) in Sect. 2, the same will be created for IEEE 33 bus distribution system. Also, the presence of priority areas in the network are the buses where the FPI is connected i.e., in IEEE 33 bus distribution network the priority buses are bus 1, 2, 3 \& 6 .

\subsubsection{Comparison of the proposed method with IED based method}

The proposed method is compared with the impedancebased fault location method using IEDs \& FCI (FPI) [6] has been summarized in Table 4 and explained as follows:

1. The IED based method account on possible fault locations in the network i.e., the accuracy of fault 


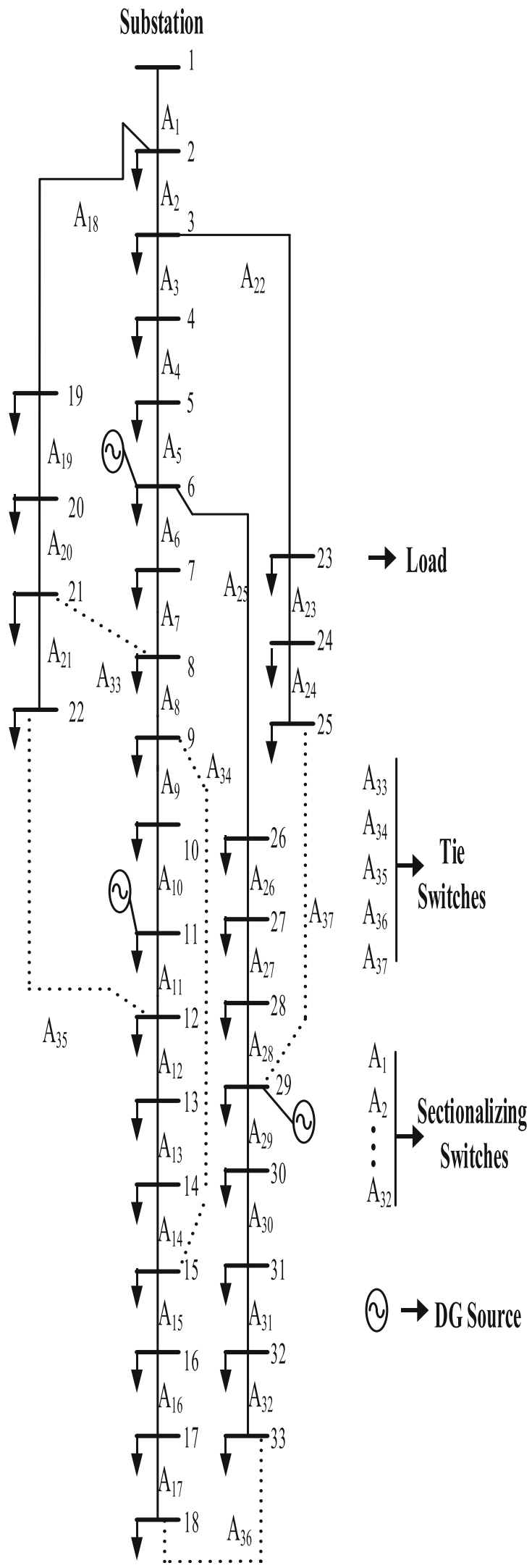

Fig. 8 IEEE 33 bus distribution network
Table 3 Line impedances of IEEE 33 bus distribution network

\begin{tabular}{|c|c|}
\hline Line number & Impedance $(\Omega)$ \\
\hline 1 & 0.1034 \\
\hline 2 & 0.5532 \\
\hline 3 & 0.4107 \\
\hline 4 & 0.4276 \\
\hline 5 & 1.0819 \\
\hline 6 & 0.6464 \\
\hline 7 & 0.7492 \\
\hline 8 & 1.2682 \\
\hline 9 & 1.2796 \\
\hline 10 & 0.2070 \\
\hline 11 & 0.3943 \\
\hline 12 & 1.8678 \\
\hline 13 & 0.8952 \\
\hline 14 & 0.7911 \\
\hline 15 & 0.9241 \\
\hline 16 & 2.1502 \\
\hline 17 & 0.9302 \\
\hline 18 & 0.2266 \\
\hline 19 & 2.0247 \\
\hline 20 & 0.6297 \\
\hline 21 & 1.1751 \\
\hline 22 & 0.5464 \\
\hline 23 & 1.1442 \\
\hline 24 & 1.1376 \\
\hline 25 & 0.2278 \\
\hline 26 & 0.3189 \\
\hline 27 & 1.4118 \\
\hline 28 & 1.0665 \\
\hline 29 & 0.5695 \\
\hline 30 & 1.3699 \\
\hline 31 & 0.4768 \\
\hline 32 & 0.6303 \\
\hline
\end{tabular}

location is around $85-90 \%$ whereas the proposed method accuracy is near to $95 \%$ because in most of the cases the fault is uniquely located.

2. In IED based method there is no such information regarding "no-fault" condition whereas in the proposed method the master FPI status (flagged 0) gives the information to the control center personnel regarding the no-fault condition.

3. Due to presence of recloser action in IED based method for fault location, the method is only meant for overhead distribution network whereas, in the case of the proposed method, it is possible for both overhead \& underground network. 


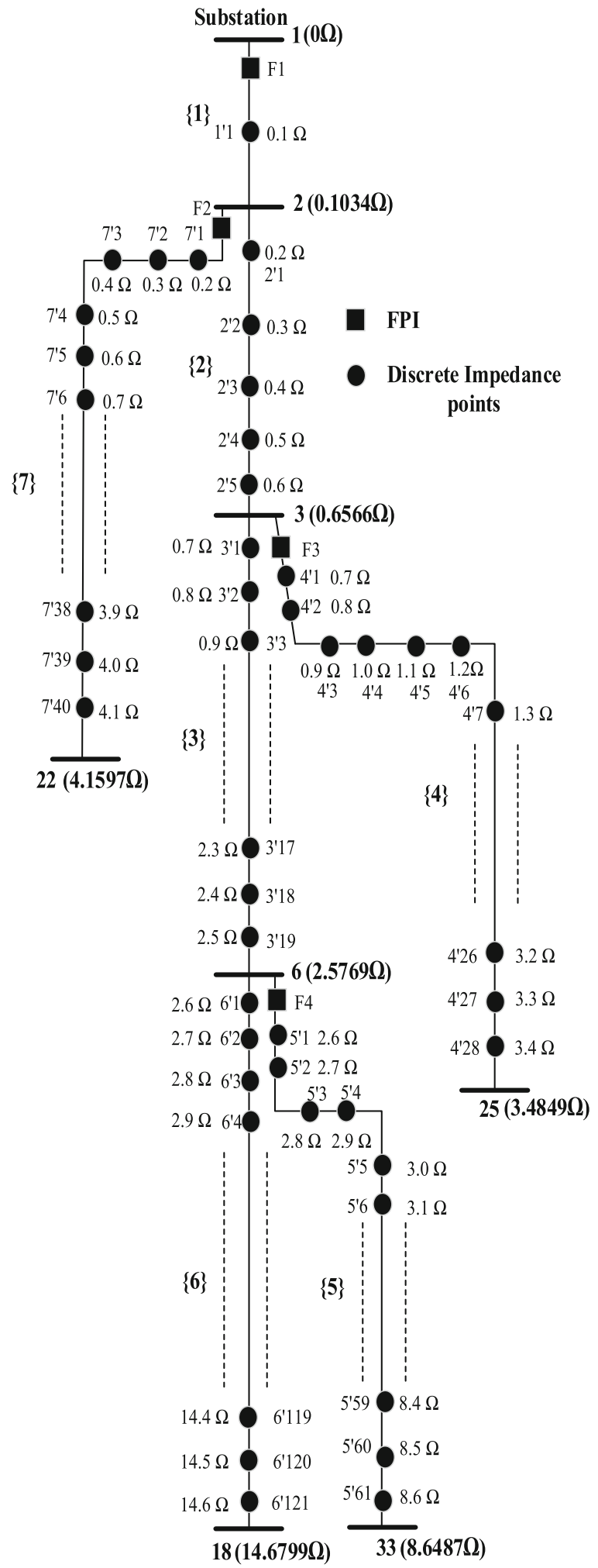

Fig. 9 Four FPI placed with discrete impedance points for IEEE 33 bus distribution network
Table 4 Comparison of the proposed method with IED based method

\begin{tabular}{lll}
\hline Analyzing aspect & IED based method & Proposed method \\
\hline Accuracy & $85-90 \%$ & $95 \%$ \\
$\begin{array}{l}\text { Detection of } \\
\text { no-fault Scenario }\end{array}$ & No & Yes \\
Type of network & $\begin{array}{l}\text { Only possible for } \\
\text { overhead distribution } \\
\text { network }\end{array}$ & $\begin{array}{l}\text { Possible for both overhead } \\
\text { and underground } \\
\text { distribution network }\end{array}$ \\
\hline
\end{tabular}

Based on the fault location by binary approach, tie switching is incorporated in IEEE 33 bus distribution network on the basis of power loss minimization.

\subsection{Tie switching or reconfiguration}

Distribution system reliability and power security are degraded heavily when any abnormality or fault occurs. Here in IEEE 33 bus distribution network faults are created at different locations and then in order to maintain of supply to each and every load, tie switching or reconfiguration is incorporated on the basis of power loss minimization.

Seven faults are created at different locations and simultaneous tie switching or reconfiguration is incorporated to maintain continuity of supply. These observations and analysis are considered by running backward forward sweep load flow analysis and are shown in Table 5.

From Table 5, it has been observed that when

i. The fault occurs at $A_{23}$, only one tie switch closing is possible i.e., $A_{37}$.

ii. The fault occurs at $A_{27}, A_{14}$, and $A_{19}$ two tie switch closing is seen but by closing tie $A_{37}, A_{34}$ and $A_{35}$ receptively, the minimum loss is observed.

iii. The fault occurs at $A_{10}, A_{7}$ and $A_{4}$ three tie switch closing are seen but by closing tie $A_{35}, A_{35}$, and $A_{37}$ respectively, minimum loss is observed.

\section{Discussion}

Fault location by FPIs using binary approach to improve nominal impedance-based methods is more advantageous over IED based fault location method as accuracy is quite higher and it can be used for any type of radial network (discussed in Sect. 5.1.1). The limitation of the study is that this fault location method by FPIs does not account for multiple faults in the network so, this aspect can be considered as a future research area for this study. Also, only power loss parameter has been taken under scrutiny in analyzing the optimal tie at the fault condition when tie switching is incorporated i.e., parameters like reliability indices, bus voltages, etc. can also be considered. 
Table 5 Fault locations and tie switching in IEEE 33 bus distribution network

\begin{tabular}{|c|c|c|c|c|c|c|c|c|c|c|}
\hline \multirow{2}{*}{$\begin{array}{l}\text { Faulted } \\
\text { line }\end{array}$} & \multicolumn{4}{|c|}{ FPI flag status } & \multirow{2}{*}{$\begin{array}{l}\text { Fault } \\
\text { impedance } \\
\text { range }(\Omega)\end{array}$} & \multirow{2}{*}{$\begin{array}{l}\text { Power loss } \\
\text { after the } \\
\text { fault (no } \\
\text { tie } \\
\text { switching) } \\
\text { in kW }\end{array}$} & \multirow{2}{*}{$\begin{array}{l}\text { Tie } \\
\text { closed }\end{array}$} & \multirow{2}{*}{$\begin{array}{l}\text { Power } \\
\text { losses after } \\
\text { the fault } \\
\text { (with tie } \\
\text { switching) } \\
\text { in kW }\end{array}$} & \multirow[b]{2}{*}{$\begin{array}{l}\text { Tie } \\
\text { chosen } \\
\text { on the } \\
\text { basis of } \\
\text { minimum } \\
\text { power } \\
\text { loss }(\mathrm{kW})\end{array}$} & \multirow[b]{2}{*}{$\begin{array}{l}\text { \% Loss } \\
\text { reduction } \\
\text { on } \\
\text { comparing } \\
\text { power loss } \\
\text { after fault } \\
\text { without tie } \\
\text { switching } \\
\text { \& with tie } \\
\text { switching }\end{array}$} \\
\hline & F4 & F3 & F2 & F1 & & & & & & \\
\hline $\mathrm{A}_{23}$ & 0 & 1 & 0 & 1 & $1.2030-2.34720$ & 910.03600 & $A_{37}$ & 172.1304 & $\begin{array}{l}A_{37} \\
(172.1304)\end{array}$ & 81.0353 \\
\hline \multirow[t]{2}{*}{$A_{27}$} & \multirow[t]{2}{*}{1} & \multirow[t]{2}{*}{0} & \multirow[t]{2}{*}{0} & \multirow[t]{2}{*}{1} & \multirow[t]{2}{*}{$3.1236-4.53540$} & \multirow[t]{2}{*}{834.10000} & $A_{37}$ & 132.8096 & \multirow{2}{*}{$\begin{array}{l}A_{37} \\
(132.8096)\end{array}$} & \multirow[t]{2}{*}{84.0774} \\
\hline & & & & & & & $\mathrm{A}_{36}$ & 141.0619 & & \\
\hline \multirow[t]{2}{*}{$\mathrm{A}_{14}$} & \multirow[t]{2}{*}{0} & \multirow[t]{2}{*}{0} & \multirow[t]{2}{*}{0} & \multirow[t]{2}{*}{1} & \multirow[t]{2}{*}{$9.8846-10.6757$} & \multirow[t]{2}{*}{384.50340} & $A_{36}$ & 114.0669 & \multirow{2}{*}{$\begin{array}{l}A_{34} \\
(92.39790)\end{array}$} & \multirow[t]{2}{*}{75.9695} \\
\hline & & & & & & & $\mathrm{A}_{34}$ & 92.39790 & & \\
\hline \multirow[t]{3}{*}{$A_{10}$} & \multirow[t]{3}{*}{0} & \multirow[t]{3}{*}{0} & \multirow[t]{3}{*}{0} & \multirow[t]{3}{*}{1} & \multirow[t]{3}{*}{$6.5203-6.72730$} & \multirow[t]{3}{*}{617.26090} & $A_{36}$ & 139.3396 & \multirow{3}{*}{$\begin{array}{l}A_{35} \\
(73.88150)\end{array}$} & \multirow[t]{3}{*}{88.0307} \\
\hline & & & & & & & $\mathrm{A}_{34}$ & 76.35050 & & \\
\hline & & & & & & & $A_{35}$ & 73.88150 & & \\
\hline$A_{7}$ & 0 & 0 & 0 & 1 & $3.2233-3.97250$ & 933.05120 & $A_{36}$ & 166.6502 & & 92.1796 \\
\hline & & & & & & & $A_{35}$ & 73.00310 & $(/ 3.00310)$ & \\
\hline & & & & & & & $\mathrm{A}_{33}$ & 75.46760 & & \\
\hline $\mathrm{A}_{4}$ & 0 & 0 & 0 & 1 & $1.0673-1.49490$ & 1243.9911 & $\mathrm{~A}_{37}$ & 143.5136 & & 88.4634 \\
\hline & & & & & & & $A_{35}$ & 157.8183 & $(143.5136)$ & \\
\hline & & & & & & & $\mathrm{A}_{33}$ & 160.3537 & & \\
\hline $\mathrm{A}_{19}$ & 0 & 0 & 1 & 1 & $0.3300-2.35470$ & 353.12300 & $A_{33}$ & 95.59170 & $A_{35}$ & 73.9674 \\
\hline & & & & & & & $\mathrm{A}_{35}$ & 91.92680 & $(91.92680)$ & \\
\hline
\end{tabular}

\section{Conclusion}

Nowadays situational awareness (SA) is very essential for any power system network. As maximum uncertainties and abnormalities occur in distribution networks, so SA plays an important role in these networks to quickly respond to the abnormities by the maintenance crew to avoid the loss of power to customers and enhancing system reliability. The information of fault occurrence is perceived by FPIs and determination of suspected locations of fault by FPI placement using binary approach to improve nominal impedance-based method in IEEE 33 bus distribution network to enhance the level 1 of SA i.e., perception has been proposed in this paper. This method reduced or even eliminated the uncertainty of fault locations in the system as it was seen in the nominal impedance-based method of the same impedance point which further enhances the situational awareness of the distribution network. The proposed method has been validated by comparing it with the IED based fault location method. Also, in regard to the faults created at different locations in the network tie switching is incorporated on the basis of power loss minimization at that particular fault to maintain continuity of power supply at every load. This accounts in the timely and corrective action plan of the operator and enhances the level 2 of SA i.e., comprehension and further after fault is cleared, network is reverted back to its original state which incorporate to level 3 of SA i.e., projection.

\section{Nomenclature}

\section{FPI Fault Passage Indicator}

$\Delta z$ Impedance step size

$Z$. Impedance between substation bus and its adjacent bus in a network

$N$ Number of combinations of FPIs flag status

$m$ Number of FPIs in a system

$S_{j}$ Suspected location of fault for $j^{\text {th }}$ combination of FPI status

$p$ FPIs flag status combinations

$q$ Total columns of flag status of each FPI and number of discrete impedance points

$q$ 'Number of discrete impedance points

$\left(q-q^{\prime}\right)$ Flag status of each FPI

$P_{x}, Q_{x}$ Active and Reactive power at bus $x$

$V_{x}, V_{y}$ Bus Voltage at bus $x$ and $y$ 
$I_{x} I_{y}$ Bus currents at bus $x$ and $y$

$I_{x y}$ Branch current between bus $x$ and $y$

$R_{x y}, X_{x y}$ Resistance and Reactance of $x y$ line

$\alpha_{\mathrm{y}}$ Set of all buses adjacent to $y$ bus towards its downstream

\section{$P_{L}, Q_{L}$ Active \& reactive power losses}

\section{Acknowledgements}

Not Applicable

\section{Authors' contributions}

TJ has carried out the research on fault susceptibility by FPI placement in distribution networks by considering different network cases and further tie switching has been incorporated so has to maintain continuity of supply. DG and DKM has been the technical adviser of the complete research work. They have supported to overcome various challenges that appeared in the work and helped in drafting the manuscript. All authors read and approved the final manuscript.

\section{Funding}

Not Applicable

\section{Availability of data and materials}

Data sharing not applicable to this article as no datasets were generated or analyzed during the current study.

\section{Competing interests}

The authors declare that they have no competing interests.

Received: 18 April 2019 Accepted: 5 November 2019

Published online: 23 December 2019

\section{References}

1. Begovic, M., Madani, V., Novosel, D. (2007, December 26) System Integrity Protection Schemes (SIPS), 2007 iREP Symposium - Bulk Power System Dynamics and Control - VII. Revitalizing Operational Reliability, Charleston, SC, pp. 1-6.

2. Panteli, M., Crossley, P. A., Kirschen, D. S., \& Sobajic, D. J. (2013). Assessing the impact of insufficient situation awareness on power system operation. IEEE Transactions on Power Systems, 28(3), 2967-2977.

3. Panteli, M., \& Kirschen, D. S. (2015). Situation awareness in power systems: Theory, challenges and applications. Electric Power Systems Research, 122, 140-151.

4. Mohagheghi, S. (2014). Integrity assessment scheme for situational awareness in utility automation systems. IEEE Transactions on Smart Grid, 5(2), 592-601.

5. Kundu, P., \& Pradhan, A. K. (2016). Enhanced protection security using the system integrity protection scheme (SIPS). IEEE Transactions on Power Delivery, 31(1), 228-235.

6. Gong, Y., Guzmán, A. (2011) Distribution feeder fault location using IED and $\mathrm{FCl}$ information, 64th Annual Conference for Protective Relay Engineers, College Station, TX, pp. 168-177.

7. Abo-Shady, F.M., Alaam, M.A., Azmy, A.M. (2013) Impedance-based fault location technique for distribution systems in presence of distributed generation, IEEE International Conference on Smart Energy Grid Engineering (SEGE), Oshawa, ON, pp. 1-6.

8. Salim, R. H., Salim, K. C. O., \& Bretas, A. S. (2011). Further improvements on impedance-based fault location for power distribution systems. IET Generation, Transmission \& Distribution, 5(4), 467-478.

9. Mora-Florez, J., Melendez, J., \& Carrillo-Caicedo, G. (2008). Comparison of impedance based fault location methods for power distribution systems. Electric Power Systems Research, 78(4), 657-666.

10. Ho, C., Lee, T., \& Lin, C. (2011). Optimal placement of fault indicators using the immune algorithm. IEEE Transactions on Power Systems, 26(1), 38-45.

11. Farajollahi, M., Fotuhi-Firuzabad, M., \& Safdarian, A. (2018). Deployment of fault Indicator in distribution networks: A MIP-based approach. IEEE Transactions on Smart Grid, 9(3), 2259-2267.

12. Farajollahi, M., Fotuhi-Firuzabad, M., \& Safdarian, A. (2019). Simultaneous placement of fault Indicator and sectionalizing switch in distribution networks. IEEE Transactions on Smart Grid, 10(2), 2278-2287.
13. Shahsavari, A., Mazhari, S. M., Fereidunian, A., \& Lesani, H. (2014). Fault Indicator deployment in distribution systems considering available control and protection devices: A multi-objective formulation approach. IEEE Transactions on Power Systems, 29(5), 2359-2369.

14. Usida, W. F., Coury, D. V., Flauzino, R. A., \& da Silva, I. N. (2012). Efficient placement of fault indicators in an actual distribution system using evolutionary computing. IEEE Transactions on Power Systems, 27(4), 18411849.

15. w3.siemens.com. (2016). SICAM FPI - Digital Grid - Siemens. [online] Available at: https://w3.siemens.com/smartgrid/global/en/products-systemssolutions/substation-automation/short-circuit-indicator/pages/sicam-fpi.aspx [Accessed 8 Jul. 2019].

16. download.schneider-electric.com. (2018). [online] Available at: https:// download.schneider electric.com/files?p_enDocType=User+guide\&p_File_ Name=NT00240-FR-EN-08+-+Flair+21D+User+manual.pdf\&p_Doc_Ref= NT00240 [Accessed 8 Jul. 2019].

17. De Almeida, M. C., Costa, F. F., Xavier-de-Souza, S., \& Santana, F. (2011) Optimal placement of faulted circuit indicators in power distribution systems. Electric Power Systems Research, 81(2), 699-706.

18. Chollot, Y., Mecreant, J., Leblond, D., \& Cumunel, P. (2017). New solution of fault directional detection for MV fault passage indicators. CIRED - Open Access Proceedings Journal, 2017(1), 1326-1329.

19. Altonen, J., Wahlroos, A., \& Vähäkuopus, S. (2017). Application of multifrequency admittance-based fault passage indication in practical compensated medium-voltage network. CIRED - Open Access Proceedings Journal, 2017(1), 947-951.

20. Mršić, P. et al. (2018) Minimization of power interruption time in MV distribution networks with fault locators based on optimal placement of fault passage indicators, 2018 International symposium on industrial electronics (INDEL), Banja Luka, Bosnia and Herzegovina, pp. 1-7.

21. Zeljković, Č. et al. (2018) Performance assessment of fault locators and fault passage indicators in distribution networks by the non-sequential Monte Carlo simulation, 2018 International symposium on industrial electronics (INDEL), Banja Luka, Bosnia and Herzegovina, pp. 1-7.

22. Atteya, I. I, Ashour, H, Fahmi, N. \& Strickland, D. (2017). Radial distribution network reconfiguration for power losses reduction using a modified particle swarm optimization. CIRED-Open Access Proceedings Journal, 1, 2505-2508.

23. Savier, J. S., \& Das, D. (2007). Impact of network reconfiguration on loss allocation of radial distribution systems. IEEE Transactions on Power Delivery, 22(4), 2473-2480.

24. Baran, M. E., \& Wu, F. F. (1989). Network reconfiguration in distribution systems for loss reduction and load balancing. IEEE Transactions on Power Delivery, 4(2), 1401-1407.

25. Ching-Tzong Su, \& Chu-Sheng Lee. (2003). Network reconfiguration of distribution systems using improved mixed-integer hybrid differentia evolution. IEEE Transactions on Power Delivery, 18(3), 1022-1027.

26. Das, D. (Jan. 2006). A fuzzy multi-objective approach for network reconfiguration of distribution systems. IEEE Transactions on Power Delivery, 21(1), 202-209.

27. Rao, R. S., Ravindra, K., Satish, K., \& Narasimham, S. V. L. (2013). Power loss minimization in distribution system using network reconfiguration in the presence of distributed generation. IEEE Transactions on Power Systems, 28(1), 317-325.

28. Chang, G. W., Chu, S. Y., \& Wang, H. L. (2007). An improved backward/ forward sweep load flow algorithm for radial distribution systems. IEEE Transactions on Power Systems, 22(2), 882-884

29. Sunisith, S. and Meena, K., 2014. Backward/Forward sweep based distribution load flow method. International electrical engineering journal (IEEJ), 5(9), pp. 1539-1544.

30. Hameed, F., Al Hosani, M., \& Zeineldin, H. H. (2019). A modified backward/ forward sweep load flow method for islanded radial microgrids. IEEE Transactions on Smart Grid, 10(1), 910-918.

31. Ameli, A., Bahrami, S., Khazaeli, F., \& Haghifam, M. (2014). A multiobjective particle swarm optimization for sizing and placement of DGs from DG Owner's and distribution Company's viewpoints. IEEE Transactions on Power Delivery, 29(4), 1831-1840. 